\title{
The Theory of Brain-Sign : A Physical ALTERNATIVE TO CONSCIOUSNESS
}

\author{
Philip Clapson* \\ Department of Philosophy, Durham University, Old Elvet, UK
}

\begin{abstract}
Consciousness and the mind are prescientific concepts that begin with Greek theorizing. They suppose human rationality and reasoning placed in the human head by (in Christian terms) God, who structured the universe he created with the same kind of underlying characteristics. Descartes' development of the model included scientific objectivity by placing the mind outside the physical universe. In its failure under evidential scrutiny and without physical explanation, this model is destined for terminal decline. Instead, a genuine biological and physical function for the brain phenomenon can be developed. This is the theory of brain-sign. It accepts the causality of the brain as its physical characteristics, already under scientific scrutiny. What is needed is a new neurophysiological mapping language that specifies the relation of the structure and operation of the brain to organismic action in the world. Still what is lacking is an account of how neurophysiologies in different organisms communicate on dynamic, i.e. unpredictable, tasks. It is this evolved capacity that has emerged as brain-sign. Thus rather than mentality being an inner epistemological parallel world suddenly appearing in the head, brain-sign, as the neural sign of the causal status of the brain, facilitates the communicative medium of otherwise isolated organisms. The biogenesis of the phenomenon emerges directly from the account of the physical brain, and functions as a monistic feature of organisms in the physical world. This new paradigm offers disciplinary compatibility, and genuine development in behavioral and brain sciences.
\end{abstract}

Key word s: action theory; brain-sign; consciousness; eliminativism; neural communication

\section{IN TRODUCTION}

In 2004, BBS (Behavioral and Brain Sciences) published two particular papers consecutively for review (27:5). It was because of their content, I expect, that an editorial decision was made about this juxtaposition. The papers were: What to say to a skeptical metaphysician: A defense manual for cognitive and behavioral scientists, by Don Ross and David Spurrett; and The Illusion of Conscious Will, by Daniel Wegner. The Ross/ Spurrett paper concerns the significance of conscious causation to the named sciences (though the word mental is used predominantly rather than conscious), and the Wegner paper (a précis from his book, 2002) proposes that conscious will is not causal.

"Correspondence to: Philip Clapson, e-mail: philip.clapson@durham.ac.uk Received April 28, 2011; accepted May 15, 2011; Act Nerv Super (Praha) 53(3-4),101-19. In 2011 the editors at ANS invited me to publish paper written in 2006 (in the present form slightly edited) revealing my developing attempts to present a finished version of the theory of brain-sign. This paper is a stage on the route. I hope the reader will approach it in this way, and find it interesting. 
These papers, and the commentaries on them, reasonably represent aspects of the current state of the topic of consciousness. Thus they are a convenient starting point for this paper, though of course that is not the limit of reference.

For, current though they may be, they are both enmeshed in what this paper will portray as a fundamental biological error sustained in Western theorizing from the Greeks onwards. Once the specifically physical biology of organisms is clarified, their prescientific discourse can be seen to be mistaken. What can replace them is the biological ontology and function of the brain phenomenon with which they have been confused. The phenomenon will be termed brain-sign.

This paper presents (in severely attenuated form) the theory of brain-sign. With this theory we have a means of placing behavior and the brain in the physical world.

\section{CONSCIOUSNESS AND THE MIND}

Over the last fifty years, the status of consciousness in the physical universe has been keenly debated. The Ross/Spurrett paper engages in this debate directly. The thrust of the paper concerns the position developed over the years by Jaegwon Kim. As Kim says in his more recent book (2005), his concern has been the alternatives for consciousness: that in the physical universe, either it can be reduced and is causal, or it is epiphenomenal, in which case it is not causal. The difficulty is, if we wish to hold onto the notion that consciousness is causal, how is it to be reduced?

The Wegner paper, by contrast, is concerned with the empirical evidence, amassed at length, indicating that, whatever we may suppose we are doing as conscious subjects, we are not causing anything in the physical universe by will. Thus consciousness and causation are addressed in these two papers from different approaches.

\subsection{Initial remarks}

In Kim's 2005 book, he says of consciousness: "Of course, if our scheme of concepts were radically altered, the problems would be as well... To motivate the discarding of a concept, we need independent reasons-we should be able to show it to be deficient, or flawed in some fundamental way, independently of the fact that it generates puzzles and problems that we are unable to deal with" (p. 30).

The concept or theory of consciousness has been a problem from its inception. Indeed, Kim's remark is curious. For one might suppose that the puzzles and problems were guides to the reasons why the concept should be discarded. However, Kim believes there are no such reasons. He continues: "It may well be that the problem is an inexorable consequence of the tension between the objective world of physical existence and the subjective world of experience, and that the distinction between the objective and subjective is unavoidable for reflective cognizers and agents of the kind that we are" (p30/31). It is apparent that Kim simply assumes the subjective/ objective nature of consciousness without considering whether this very division is not $a$ reason for discarding the concept. After all, since Kim accepts the physical universe as what is, one might question whether there is subjectivity in the physical universe. And since it is consciousness that generates the objective for us (supposedly), one might wonder whether we really do 'have access to' the objective.

(This is not the approach to Kim that Ross/ Spurrett adopt. The main thrust of their attack on Kim's position is his supposition that fundamental physicality, as is now conceived by physicists, involves the notion of causality at all.)

Discarding conscious will, as Wegner proposes, is actually a step in discarding consciousness, though Wegner appears not to appreciate this. (I.e. the consciousness model is fatally broken.) In his response to the commentary on his paper, he states why there is such strong reaction, in some quarters, to his proposal that conscious will is illusory. It is because 
our own experience is being controverted. "The experience of conscious will is, of course, the basis of the intuition we all have that we cause our actions" (p. 681). However, what is remarkable is that Wegner makes a causal distinction between this experience, this feeling, and thought. He says that "Thoughts must cause action... This is the empirical will as defined in $I C W$. It is only when we add the experience of conscious will to the system that everything becomes murky. Heyman [a commentator] reports that $I C W$ overlooks 'the objective basis for the sensation.' It does so because the book simply assumes intelligent goal-seeking behavior on the part of humans. The experience of such behavior is the issue" (ibid., original emphasis).

In this excerpt Wegner does not explain our experience of conscious will in any ontological sense. Nor does he tell us how thought is reducible to physicality (as Kim would require) that it may be causal. Nor does he tell us why intelligent goal-seeking behavior, which is presumably associated with thought, should be objective. What does objective entail here, and specifically as thought? He does tell us that "The feeling of doing establishes a 'doer,' not only authenticating the self but constructing the self from what was previously thin air" (p680/ 681). But he does not tell us how a feeling establishes a doer (what does this mean?), or what authenticating entails (what authenticates what and to whom and by what means?), or what constructing a self from thin air could possibly entail in any scientific or ontological sense. And what has all this to do with a brain, the apparent source of all this mysterious happening?

When the commentators Bogen and Raz \& Norman complain that Wegner's piece lacks neuroscience, Wegner pleads that he is writing as a social cognitive psychologist. But his consoling reference to imaging studies ("exciting new ventures", e.g. Ito's cerebellum mediated internal feedback, p. 686) is highly speculative, since neuropsychology conducted by current fMRI imaging has no identified method by which correlations can be made between what a subject experiences and what is illuminated. I.e. if there is to be a division between physical causes (Wegner often calls these unconscious causes) and experiencing as Wegner claims (as indeed may be the case, but the latter must be still physical), then what is illuminated in the image cannot be assigned de facto to experiencing, but will likely be what is actually causal. After all, experiencing (so-called) is pervasive, and why should we not suppose that experiencing be differentiated from causal processes in the brain image, or more radically, experience of e.g. thought be not differentiated from other experiencing? Moreover, if what must be differentially apparent are the action-related physical causes in the brain, are they in fact thought? [This is a direct challenge to this kind of statement by Stent (2005). "Probably the most promising...method of advancing our understanding of the biological basis of our thoughts and feelings is brain imaging, which permits the observation of...the very parts of the living brain that are involved in the generation of mental phenomena" (p 146), reconstructed from original text.]

There is indicative evidence for the division here. In the imaging referred to by Neville et al. (1998), 'speech' areas of the brain are illuminated by hearing subjects reading, but also illuminated by deaf people watching American Sign Language (ASL), viz. the Broca and Wernicke areas in the left hemisphere. In addition, however, the superior temporal gyrus on the right hemisphere is active in response to ASL in deaf subjects, an area that would be activated in hearing subjects listening to language. We might conclude that the left hemisphere illumination does not necessarily involve experience, since it is different for each, but causal language processing which is common. We might also conclude that for hearing watchers, what would be causing the illumination in the right hemisphere of hearers hearing is not the experience (since there is none), but causal function replicated by ASL watchers who cannot hear. For hearing subjects competent in ASL also have the area illuminated when watching ASL. Further examples are in the footnote. ${ }^{1}$

\footnotetext{
${ }^{1}$ (1) Physical damage can occur without a subject feeling pain, i.e. even though signaling is taking place to, and in, the brain from the damaged areas; and pain can occur without there being any physical damage. See e.g. Wall 1999 for extensive discussion. His conclusion: "The classical theory is that the brain analyses the sensory input to determine what has happened and presents the answer as pure sensation. I propose an alternative theory: that the brain analyses the input in terms of what action
} 
Already we find no science in view, for there is no domain of discourse in which the ground rules, and identifiable law ful components, are commonly scientifically accepted (cf. Kuhn's notion of "normal science", 1962). Indeed, no agreed explanation exists for how consciousness is to be reduced (cf. Kim 2003, p. 152), or more fundamentally, what consciousness is in any scientific sense (e.g. Seager 1999; Papineau 2003). ${ }^{2}$

\subsection{Analysis}

The Ross/Spurrett paper is concerned to preserve key features of cognitive science, understood as functionalism. They regard Kim's reductionist proposal for functionalism as destructive of the very notion of functionalism. They say: "By functionalism we understand any position that assigns serious ontological status to types or states of processes individuated by reference to what they do rather than what they are made of - that is by reference to their effects, rather than (necessarily) their constituents" (p. 604). The assumption is that mental states are functional states. Such a state could be a thought, as Wegner has it. In the camp of some theoreticians, it may be distinguished from a feeling, as of conscious will, which is causally problematic because of its subjectivity. With some theoreticians the problem of subjective states certainly applies to qualia (e.g. Block 1995; Chalmers 1996). Ross/ Spurrett intend to preserve causal ascription to mental states, and presumably they would class a feeling as functional and causal too: they deplore Chalmers' conservative metaphysics that results in dualism, they say.

But without taking biology into account, is functionalism a valid approach, not merely in terms of biology's capacity to realize mental states as causal physicality, but in endorsing the concept of mentality at all? Or, co-opting David Martel Johnson's words, "Compared with structuralist and behaviorist investigators they claim to have refuted, present-day cognitivists are not in as good a position to propose and defend any single, precise concept of what the mind is" $(2005$, p . 5). Surely without a precise and biological concept of the mind, pursuing a scientific theme is futile. Is it not reasonable to say that cognitive science (as Ross/ Spurrett conceive it), with its mentalist assumptions, is batting on the wrong wicket; that the revolution Chomsky was a major player in initiating, from behaviorism back to mentalism, was the wrong move? ? $^{3}$ am going to raise three fund amental objections to mental states.

\subsubsection{The cultural/historical derivation}

It might seem hardly necessary to point out that the notion of mental states does not derive from a scientific view of the universe. That we live with a cultural assumption about the mind is surely widely understood. But current discourse indicates that its significance is not understood at all.

\footnotetext{
would be appropriate" (p176). (2) For discussion of anomalies where brain activation in the ventral stream processing areas may or may not generate visual experience, see e.g. Dehaene \& Naccache, 2001, and discussion of their paper (and others) by Block in the same volume. But the conclusion we draw is not that experiencing requires an additional neural X; nor is there a multiple conscious possibility-phenomenality, access or reflexivity-as does Block. Rather there are two different neural functions, as discussed subsequently. (3) The claim by Andy Clark and Jesse Prinz (2004, p67) that the recently well-publicized capacity of a paralyzed patient to move a cursor about on a screen is by thought (a supposition widely assumed in the press), as a result of electrodes inserted in the brain, is quite unfounded. As we shall propose, what causes the move of the cursor are the physical brain states at which the electrodes are directed, and the sense of thought is a resulting reporting of the brain status, but not to a causal mental subject.

${ }^{2}$ It is fairly common practice not even to specify what is meant by consciousness, but to proceed as if it is an adequately accepted scientific fact. This is true of the Churchlands (PM 1995, PS 2002), and Christoph Koch (2004). J Graham Beaumont (1999) states more appositely: "Neuropsychology is in a conceptual morass. Neuropsychologists seek to study the relation between brain and mind, but without really addressing the status of these two constructs, or what potential form the relation between them might take" (p527).

${ }^{3}$ A key document referred to is Chomsky's (1959) review of B.F. Skinner's Verbal Behavior. Skinner's behaviorism was tied to too limited a set of underlying notions. Language is discussed here at 3.2.4.
} 
To be extremely synoptic: The mind begins with the Greeks. The theory is that placed in the human head is a correspondence to what lies behind the physical world, nous (intelligence, reason, etc.) corresponding to the universe's Nous, and logos ([logical] thought/ speech) corresponding to the universe's Logos. In the Christian version, God, being the creator of the universe, naturally 'thought' the essence of things, and this kind of capacity was placed by him within, or as, the human mind. (Further below 2.2.3, \& note 6.) With Descartes, the idea is developed, based upon the medieval integration of the Greek ideas with the Christian soul. Now the intellect, and sensation and feeling, are properties of the human mind. Its capacities are endorsed specifically by God. Thus Descartes can claim both objectivity (for science), because what he thinks is underpinned by God who has made everything and therefore knows it, and proper ontology, because the mind is not part of the physical universe but in a spiritual realm roughly equivalent to God, which is how thought (ideas) can be objective and certain. Egoism (my soul) becomes (problematically) a theme of Western philosophy/psychology.

Now Ross/ Spurrett and Wegner, and Kim too, may suppose we 'naturally' think the way we do about the mind. But 'naturally' here cannot mean 'unalloyed by the Greek/ Christian tradition'. We may pay lip service to the notion that the mind must be physical, but we retain in large part precisely the Greek/ Christian tradition (including materialists like, yes, Dennett (1991a; 1996) and the Churchlands (PM 1995; PS 2002)).

In Kim's approach there is a mind and it is problematically related to the physical world, and there are only two options concerning it: Either it is reducible or epiphenomenal. But this very specification of the mind may be seen as a false dichotomy via the Greek/Christian tradition. For nothing in that tradition bears any relation to the physical universe. I.e., although subsequent to Descartes there has been dissolution of aspects of his theory, in principle it remains as it always was - about another kind of existent.

After all, what causes us to think as we do about the mind (traditional or not) must itself be a physical process, and to suppose we have an option about what we think - that we (the mind) have some freedom in this by contrast with states of the physical universe (a Kantian $(1781,1789)$ distinction solidly within the tradition) - is already to deny the characteristics of the physical universe. Part of coming to grips with the physical universe as what is involves appreciating what 'being a tradition' entails, and what any theory can be for us as physical organisms.

The point here is that, because of our cultural attachment to consciousness and the mind, a biological analysis of the neurophysiological phenomenon within the terms of the physical universe is actually obfuscated.

\subsubsection{The predicament}

Both Kim and Wegner assume that we have self-knowledge. In Kim's terms we are "reflective cognizers", and in Wegner's terms we experience (i.e. we are knowingly aw are of) our conscious will. Thus there is a state of consciousness and there is a state of consciousness of $i t$. This is Descartes' model in that the mind's subject can interrogate (reflectively) its content, where the content precedes (structurally) the ensuing interrogation.

Since Dennett uses the term 'mind', we should present his materialist position of 'mental content'. Dennett (1991a, 1991b) proposes the brain represents (a "real pattern"), and it (i.e. not a self) is a judgment that can be causal as a representation (or, again, a discrimination). By eliminating the conscious self (ontologically) in this way, Dennett intends to remove the problematic aspects of subjectivity (including an infinite regress of homunculus explanation), and coincidentally the possibility of phenomenology, i.e. the privileged interior availability of content to the self, the Cartesian Theater as he has styled it. ${ }^{4}$

\footnotetext{
${ }^{4}$ The problems with Dennett's position are widely commented. To quote a passage with familiar elements. "Mental contents become conscious not by entering some special chamber in the brain, not by being transduced into some privileged and mysterious medium, but by winning the competitions against other mental contents for domination in the control of behavior,
} 
But the question is not whether prima facie these accounts could be understood as physically realizable, but whether the (mentalist) words knowledge or judgment used in the accounts apply to (physical) biological organisms. And more precisely: To the biological organismic phenomenon that is me. What is pointed to here is the predicament we face in being this phenomenon in the physical world.

Here is a specific example of the predicament. I stand before a tree. I see the tree. What I see, however, is not what is there. I am in a mental state which has the tree as its perceptual content. The perceptual state, which I call seeing the tree, is actually an artifact of my brain. I have no way of escaping my position to verify either that the tree I see is what is there, or that I see it. More precisely, the state of experiencing (so-called) which I am is also the state of appearing which is of both the tree and myself; and the latter is as the experiencer of the tree and of myself (reflectively). In other words, although it might seem that I react to the tree because I see it, and I react to it as such, in my predicament I cannot escape to the realm of knowledge or judgment (that Kim et al. or Dennett claim) because I cannot exit my condition as which I am (so-called) experience and appearance. Indeed, the very claim that my mental state is causal, either as a knowledge capacity of perception, or a judgment of my brain, depends for its plausibility upon a condition to which I cannot aspire. For me (the phenomenon), there is no ind ependent level for my causal claim.

This is not a hopeless situation. It is not hopeless (in this sense) because clearly we go on: we exist now and we will tomorrow. Things work (as they do for apes, dogs, fish, worms, amoeba, etc.). However, there is an analogy to be found in our predicament with the Copernican revolution. Placed as we were upon the earth, we could not see (perceptually) that the earth goes round the sun. But by scientific enquiry, we could find evidence for it. Our predicament here (more fundamentally) is as experiencers-appearers. What we need is a theory which deals with the predicament as the brain has engineered it, one for which there is evidence.

What we cannot do by contrast (but is the Greek/ Christian tradition), is presuppose that our experiencing-appearing gives us the concepts of the mental, including its causality, because we cannot take for granted, biologically, that anything can be presupposed about what the phenomenon is. After all, science informs us that the colors we see do not exist in the world; that the universe is not three dimensional as it appears; that the solid objects we see are actually regions of space populated by highly active microstructural units; and so on. Indeed, as Wegner's book illustrates, and Freud proposed a hundred years ago, it is often the case that there is no correlation between our experience-appearance (including thought!) and what we do. We cannot just refine our notion of mental states (e.g. divide them into the conscious and non-conscious). We must find a biological theory that clarifies the phenomenon fundamentally. And that $i$ problematic, for the phenomenon cannot provide us with its self-interpretation: the predicament indicates that we cannot assume an $u s$, the egoistic (mental) knower or (physical!) judger, to whom it could do so. To repeat, the Greek/ Christian tradition is not founded on the principles of a physical universe.

\footnotetext{
and hence for achieving long-lasting effects—or as we misleadingly say, 'entering into memory.' And since we are talkers, and since talking to ourselves is one of our most influential activities, one of the most effective ways for a mental content to become influential is for it to get into the position to drive the language-using parts of the controls" (1996, pp205/206). 1) How does the brain ('mere' physical states) create (synthesize?) 'mental content'? 2) How do (Oliver Selfridge's) mental contents compete with each other and win: i.e. by what physical process as content? [3) Dennett's notion of 'celebrity' for mental content is consciousness defining itself in its own terms, not explaining itself by an ontologically more fundamental process.] 4) How does content enter into memory, even if we misleadingly so specify it? 5) How do we talk to ourselves? Who is doing what to whom? (We understood there was no self.) 6) How is behavior controlled by mental content: i.e. once having become content (e.g. a belief), how does this (as yet unexplained) physicality as intentional exercise physical control of motor actions? 7) What does "drive the language using parts of the controls" entail in any physically expressible sense? And so on.

The imprecision in Dennett's presentation, by which he claims to be talking of physicality yet slides seamlessly into mentalist and personal terms, gives the lie to the fact that he has any physical theory (a point made by e.g. Seager 1999), but is rather strenuously trying to subvert Cartesian materialism amongst his contemporaries. Interestingly, in his comments (2004), he criticizes Wegner for precisely the same ontological imprecision.
} 


\subsubsection{The physical universe}

Now we note what the predicament seems to imply. Is all enquiry hopeless because we cannot place the function of consciousness, the function upon which we supposedly rely to found our knowledge, and which in our everyday activity we rely upon to act? No, we stated, because things appear to go on working, including some of our theories. But it seems very difficult to suppose the theories we have about the universe that seem to work do not rely upon the fact that we seem to have them: e.g. the theory of special relativity of which I am now thinking. Even if we have no convincing explanation of how the brain can generate, or be, this thought, how can we deny this thought exists? I am having it now!

What the predicament example demonstrates, however, is that the conviction of our having this thought (or seeing this tree) is itself placed within a biological actuality to which the conviction (the state of being convinced or certain) cannot access. The predicament might be held to lead to Cartesian doubt or Humean skepticism, but it is neither of those. It is already a construct in a biological theory of the brain in a purely physical world; a theoretical position which subverts the claim that consciousness must be self-revealing of itself, the world and ourselves, and other attributes like its causality. The theory indicates that Kim's foundational point about consciousness, i.e. objectivity vs. subjectivity, is not presupposable, since Kim would first have to have a biological theory of the phenomenon to make such a claim, if he really acknow ledges the physical universe is what is.

The physical universe, as science conceives it, exists as the properties of mass/ energy space-time. It constantly changes as its conditions change. It is at each instant. A feature of the physical universe is biological organisms. They, too, are at each instant. They evolve in the manner of natural selection; they survive by their fitness in the environment, and their ability to reproduce. The function of organisms, if one can ascribe function to them, is to survive and reproduce. Their adaptational capability is a factor in their survival. A factor in their adaptational capability is their memory, rendering behavior modification according to previous interaction with the environment. Memory, as initially identified by Donald Hebb (1949) (i.e. before he turned it into neuropsychology), means neural modification. Behavior, or action, is what enables survival by the organism. Behavior is not only modified interaction with the environment; it is also learned by interaction with parents and others. Learning is the modification of neural structure, and the recent identification of mirror neurons (Rizzolatti et al. 1996) has given support to this notion.

Nowhere in this extremely synoptic version of organismic biology as physicality is there a place for a causal psyche, or psychology-perceptions, thoughts, feelings, sensations, beliefs/ desires, etc. The problem for us in grasping the actuality of the physical universe (apparently, but this is the Greek/Christian supposition) is that we (as the phenomenon) seem to inhabit a different state from it. But there are two analogies that may help us move beyond this: the first, already mentioned, Copernicus vs. the Aristotelian/Ptolemaic universe; the second, Darwin's evolutionary theory which discounted any privilege to humans in their biological emergence.

We must add to our predicament as the brain phenomenon, as so far discussed. For not only can we not justify our theories by (the mentalist properties of) knowledge or judgment because of the nature of our predicament; in fact we cannot suppose any causal property exists for the organism from the phenomenon for precisely the same reason. As the phenomenon, I am in being at each instant, like everything else in the physical universe. Nothing I am as the phenomenon causes my next appearance and the appearance of the world as me as the phenomenon. I do not cause my appearance as the phenomenon when born, and I do not cause its dissolution when I die, and I cause nothing in between. What causes my appearance is the physicality which it is, and to argue that the phenomenon is a physicality (called the mental) and thus is causal is already to separate it out from physicality to identify its causality, which is quite absurd if one accepts that the phenomenon is physical.

If there is causality for the organism as physicality, it lies in the properties of mass/ energy space-time; and whilst there may be properties of consciousness which cannot be accounted 
as causal physicality for the organism, that does mean the brain phenomenon is not physical, because its properties could entail causality in another way. ${ }^{5}$ In that way of being, the phenomenon can be entirely reducible as (i.e. not to) physicality as Kim requires, but still not be causal for the organism and not epiphenomenal.

This argument should be quite acceptable to Kim, because he begins his account from this position: the distinction between vertical and horizontal causality, from his mentor Jonathan Edwards (Kim 2005, p. 36-38). The problem is, Kim does not think in terms of biology, but entirely within the Greek/Christian tradition, and that is a hopeless framework for interpreting the organism in the physical universe. What we need here, to remove the impasse, and identify how we can genuinely arrive at a science (and understand what a science can be for us as physical organisms, and what the word 'understand' entails, \& etc.), is a Kuhnian (1962) change of paradigm.

\subsection{Summary}

It is not, as Wegner says, that our experience of the will makes us think it causal. The metaphor for consciousness, stretching back at least to the Greeks, is being in the light. ${ }^{6} \mathrm{We}$ (as organisms) are illuminated in the world lit up for us as consciousness. The impetus for mentalism is the notion that, being in the light, our rational actions (thought rather than feeling) result, for everything is available to the (causal) rationality that consciousness confers: hence the use of the term access, by e.g. Block 1995 or global accessibility 2001, and distinguished from the egoismic phenomenal. ${ }^{7}$ Hence, indeed, cognitive science. As old as the Greeks, and still not comprehensible. For light is not an intrinsic property of electromagn etic radiation: it is just (brain-made) what we see (so far undefined), or facilitates our seeing; it confers no access as knowledge (where knowledge is taken as: representation of what is to a subject).

Our analysis offers a different interpretation. If the phenomenon is physical, and not merely supervenient upon the physical, then its causality results from its being physical. But it is not, as Davidson (1970) attempted to compromise, that mental events cause physical events in a law-like manner only under physical description. Being physical, the phenomenon itself (as a state) must be describable as physicality (i.e. what is a physical thought, a physical feeling? and why are they not necessarily causal?). Therefore if the phenomenon has causal implications, its nature as physicality must be revealed, not fudged as some unanalysable (i.e. hermetically self-defining) supervenient feature. ${ }^{8}$ It will not be causal for the organism because its function is not mass/ energy space-time, though its existence is. And because of this, we do not conclude that no causality is involved in its function. To clarify this requires explicating the biology. ${ }^{9}$

\footnotetext{
${ }^{5}$ This is not intended to preclude causality in the organism which does not include the brain.

${ }^{6}$ An obvious reference is to the Cave Parable in Plato's Republic. But that is preceded by (not least) the Presocratic fragment 64 in the Diels-Kranz numeration of Heraclitus, translated as "Thunderbolt steers all things" (Kirk et al. 1983, p197/198); or as Heidegger (1975, p72) interprets it: "But lightning steers (in presencing) the totality (of what is present)". For discussion on the relation to Zeus and earlier notions of the divine sun, see Kirk et al. (pp198-200).

${ }^{7}$ The notion that content is accessible, i.e. causal, while phenomenal states, or qualia, are not depends upon an a priori definition of mentality, rather than what it could be physically. But since there is no explanation offered of what mentality is causally as physicality (or not), the distinction lacks physical plausibility (cf. note 20).

${ }^{8}$ The widespread notion that mental states are propositional attitudes offers no explanation, biologically, of what they are. As Dennett (1994) says: "The most sweeping conclusion I have drawn on the theory of content is that the large and well-regarded literature on propositional attitudes... is a disciplinary artefact of no long term importance whatever, except as history's most slowly unwinding unintended reductio ad absurdum"( p241).

${ }^{9}$ There is no analogy here with Dennett's (1991b) use of abstracta for beliefs.
} 


\section{THE THEORY OF BRAIN-SIGN}

What characterizes a Kuhnian-type revolution is a reassessment of the fundamentals. The theory of consciousness specifies two kinds of causality for the brain: the realm of physicality which is neurophysiology (often ambiguously termed unconscious), and another realm which is the properties of consciousness. Instead we propose one realm of causality for the brain, electro/ chemical neurophysiology. But there is another physical function. And that involves a physical feature: the brain phenomenon we are pursuing. Its causality is to be understood in a different way, a way revealed by explicating the biology.

The first point reinforces a previous one. There is nothing voluntary about our so-called experiencing. When I open my eyes, I cannot choose what to see. My seeing is a given. There is a supposition amongst some that I can choose what I thin k. But there is no means by which I can choose what I think: each appearance of a thought is a given; there is no step at which I can insert an independent choice. (What could that mean?) The sense of choice (as Wegner's feeling of conscious will) is itself a given (i.e. part of the biology, as conviction above, 2.2.3). Nor can I choose what I do. Although it might appear that I consider options, and amongst those options make a choice, the sequence of the consideration or choosing is not something during which I can insert an independent evaluation, or alter what happens. ${ }^{10}$

Of course, freedom as spirit, soul or mind was a key feature of consciousness. The retention of this prescientific notion exists in Dennett's materialism. In fact, Dennett is a materialist dualist, since his account retains the ghost of freedom beyond physicality. But if consciousness is physical, it is wholly determined, and thus the mentalist word experience (which he uses constantly) is fallacious (as we shall see), since that would imply a (dualist) self capable of independent (i.e. free) activity as a result of being an experiencer in its inner (Cartesian?) realm.

While there is a brain paradigm that is consciousness, the organism does not relate physically to the world, but to a simulacrum of the world, now not endowed by God, but by the brain's own manufacture-under some obscure (i.e. without physical explanation) principle. We do not thereby grasp the physical organism per se, nor its modus operandi under evolutionary principles. ${ }^{11}$ A Kuhnian-type revolution will not be towards an arcane or strange alternative to the prevailing view (which itself is arcaneand strange). It will restore the terms of science: physicality and physical explanation, and the theory of evolution.

\subsection{An action theory of the brain}

A biological theory grants the brain the capacity to cause action for the organism in its encounter with the physical world. Brain science, therefore, must explore how the brain achieves this in its physical structure and operation. It is not that, currently, neurobiologists and neuroscientists do not engage this task. It is that their work is hampered by the attempt to determine psychology in the brain, as if that were a causal mechanism to be accounted for (cf. 2.1, \& notes 2\&11). Ross/ Spurrett, for example, suggest that consciousness results from the effects of dynamic systems theory. But whether that theory, or connectionism, or a combination of these and many other kinds of physical causality are relevant to the brain's activity, none of them either explain consciousness, or contribute to finding psychology in the brain; or, more fundamentally, justify the notion of consciousness in the first place (cf. Seager on Dennett, note 4).

\footnotetext{
${ }^{10}$ The topic here relates to the notion of free will. Books continue to be written, including one edited by Gary Watson in 2003. However, his earlier statement (1995) could not be more apposite, or more indicative of why this is a non-topic. "While subsequent developments have sharpened and focused the issues, the basic questions remain what they were in the seventeenth century" (p181). Exactly.

${ }^{11}$ In their widely read student text, Bear et al. (2006) state: "Exactly how the parallel stream of sensory data are melded into perception, images and ideas remains the Holy Grail of neuroscience" (p421). The use of the expression "Holy Grail" (unintentional though its irony is) exemplifies the prescientific ground that is being taught to our young people.
} 
The brain adapts to the world it encounters for the function of survival and reproduction. In so doing, it builds action programs to control the organism, which are endlessly repeated (cf. e.g. Edelman \& Tononi 2000). ${ }^{12}$ Building action programs is by various methods: innate capacities, trial and error, feedback, mimicking of parents, etc. Pursuing this is a valid procedure for brain science.

What is required is a new neurophysiological language that maps brain structure and operation to the actions of the organism in the fulfillment of its biological function. This will not be in the intentional language of psychology. It will likely be a description of nested and overlapping structures and states within, below, above and apart from the individual neuron level. In divesting action of intentional categories, there also needs be a significantly enhanced description of categories of action in the world.

This new neurophysiological language does not depend upon an assumption of our own consciousness in its expression. Indeed, whatever allows us to render this non-intentional description of brain causality is other than consciousness. Now we want to know how that is achieved. So we turn to...

\subsection{The rationale for brain-sign}

Without moving from the physicality of dynamic systems theory, or connectionism, etc. as possible expositions of causality, we find the neurophysiology of the brain facing a fundamental problem. It is not that it is embedded in the world of its action, and therefore requires some symbolic means of processing its information independent from the embedding (why would it need that?). ${ }^{13}$ Nor does it need to (or could) create a workspace of mental properties that somehow interact and are available (globally!) to purely physical properties. (Descartes' unsolved interactionist problem $350+$ years on.) No, the brain problem is as follows. Or rather, it is not a brain problem. What we shall describe is a feature from the evolutionary process.

\subsubsection{Brain-to-brain communication}

If we accept the brain has an action causing relation to the world for the organism, then we need no luminous causal inner state of correspondence to the outer physical world. But, then, how do our separate neurophysiologies communicate? How can purely physical states of the brain enter into collective activity? The elimination of the implausible, consciousness, seems to land us with the impossible.

\footnotetext{
${ }^{12}$ E.g. "In a...detailed model of cortical areas, which included interconnected thalamic regions, we...examined the dynamics of reentrant interactions within the thalamocortical system... That such a self-perpetuating dynamic process, characterised by the strength and speed of reentrant neural interactions, can originate from the connectivity of the thalamocortical system is of considerable significance for understanding the actual neural events that underlie the unity of consciousness" pp119-120. Edelman's notion of the re-entrancy of neural structure in being causal is the analogy for "building programs" that we are making. But Edelman's "unity of consciousness", a notion derived from Kant's transcendental unity of apperception, and by contrast with his (Edelman's) notion of neural integration (also termed binding), is causally superfluous. What remains at issue, however, is how and where the phenomenon is integrated for the function it performs, as discussed.

${ }^{13}$ Kim Sterelny's (2003) interesting book, with much empirical reference, on what he calls decoupled representations, or belieflike capacities, suffers from two problems in the context of the present paper. Since he scarcely mentions the word consciousness (with its associated ontological difficulties), we must suppose that, in using expressions like perception and sensation, or when he refers to mental operations as belief or desire, he means conscious manifestations, and not purely physical-neural implementations. But then he does not clarify why we should use the word belief (or mental) for structures that have not been shown to be causal-physical by any adequate theory. Moreover, causally, so-called beliefs/desires as so-called consciousness are not inevitably deterministic in operation, i.e. we do not necessarily act on our beliefs and desires. On the other hand, and more profoundly, if there are mechanisms that entail an organism not necessarily reacting directly to a stimulus but delaying, or as he says, having a more general usage across different kind of behavior (decoupled), why should we suppose that physicality is implementing (e.g.) a belief? For neurophysiology may cause behavior (perhaps on a large scale of neural structure/operation) which has nothing to do with an architecture of beliefs and desires, which wholly derive from what consciousness is deemed to give/be. As we say elsewhere, the notion of mental states is then fatally obfuscatory to the understanding of what the neurophysiology is actually doing. Both these problems apply to the whole literature of folk psychology.
} 
From an evolutionary point of view, this will be understood differently. Clearly (to us) the solipsistic organism is a poor organism, in that its means of environmental adaptation are severely limited. Collective action renders far richer capabilities since actions can be shared and thus be more complex so, by chance and selection, allowing species to be more fit in the environment.

What does this imply? Not that collective action is the cooperation of conscious individuals, but rather results from what we describe as a collective organism, or superorganism. From our conclusion that the action of individual organisms results from neurophysiological programs, we then suppose that collective action results from supraorganismic neurophysiological programs. In which case the interaction, the cooperation, of individual organisms is genetically endowed and learned at an individual and supraneurophysiological level. (Here is a crucial function for mirror neurons.)

Still, the situation is more complex than these statements imply because the nature of the tasks the super-organism can implement must be considered. They will be divided into two classes. These are categorized by what used to be termed closed and open instincts, but are now more customarily termed stereotypical and modifiable behavioral patterns. The closed or stereotypical category indicates an inherited genetic behavioral activity which is resistant to change under environment-exposure influence, whereas the open or modifiable category indicates that there is an intrinsic capability of modification.

We emphasize that we are not referring to the behavioral pattern of the individual, but the communication mechanism between individuals. Clearly this is a severe constraint upon the individual since, for communication to work, the cooperation of a population of individuals is required under some stability, whereas an individual's modifiability (or adaptability) in its ow $\mathrm{n}$ actions concerns only itself.

\subsubsection{Two classes of communication}

Taking this point as analytically crucial, what we propose is that, whereas there are insect groups which are socially complex (e.g. bees, ants, termites), their interactions are not dynamic. This is because the effects of their social activities can be achieved from stereotypical behavioral communications. On the other hand other species can cooperate in tasks where the behavior of the interaction is not by nature stereotypical. Thus although what is achieved as a society may even seem less impressive, the capacity for interaction requires a fundamentally different modality.

The contrast to be drawn is between bees and hunting lions. This will be used as a paradigm example. In both cases the causal properties of the action taken, both individually and cooperatively, lie with the neurophysiology of the organisms' brains. In the case of the bee dance, the signing bee's brain causes it to perform the appropriate movements, even in the darkness of the hive, which will modify the receiving bee's neurophysiology such that it will set off in pursuit of the nectar. The stereotypical communication is the means of this behavior modification, although the actual signing will vary depending upon what directions are being conveyed. The bee's search may involve different kinds of cues, including the position of the sun and landscape indicators. But we do not suppose anything more than neurophysiological reaction to the physical cues are necessary, obtained by sensory input. There is no evidence (e.g.) that bees have mental maps of the landscape (cf. Sterelny's literature discussion, 2003). Nor do we suppose that bees think about what they are doing.

\subsubsection{The brain-sign requirement}

The question arises, therefore, whether more unpredictable communication requires (mental) perception or thought or feeling. We consider this in relation to lions who can hunt cooperatively. What distinguishes the communication situation with lions from that of bees is 
that, in the cooperative act of lions, there is an essential uncertainty or imprecision during the hunt. For, since each lion takes account of the movements of the prey (zebra or gazelle, etc.), and the other lions' movements, and the terrain upon which the hunt takes place, there cannot be, in the same way as with bees, a stereotypical communicative mechanism. It remains the case that the neurophysiology is doing the causal work for the ind ividual lion with sensory input, and this is to be seen as in the nature of a super-organism. And if the super-organism were genuinely that, then the hunt process could be completely conducted by the neurophysiology of the super-organism. But there is an absolute divide between the nodes of the super-organism, i.e. the physical distance between each individual lion's brain. Therefore a new factor is introduced.

There is a requirement, or more precisely, an evolved capacity for neural signification to take place between these nodes (i.e. in the brain of each lion) that, as it were, closes the loop of the causal process (in principle). The signification is of the continually changing causal neural status of each lion's brain. For lion A, the view of the world it receives during the hunt process is the sensory input of the zebra on the terrain and the other lions (B and C). Whilst lion A's neurophysiology controls what it does as an organism in response, it also causes a sign in its brain of the 'view' to which it is responding. By this means, all the lions' neurophysiologies are linked both causally and signifyingly in the process of the hunt. Moreover, we may suppose that lion A's brain also has an internal (as opposed to external) element, the response to physical activation in relation to the hunt, which may be coded as part of the neural sign along with the scene, what we mis-term excitement. The whole neural sign we term brain-sign, and it replaces the notion of consciousness for the neural phenomenon.

This is a novel concept, so recapitulation may help. In the case of bees, communication is straightforward, in that the sign conveyed in the world by the movements of the signing bee can be absorbed by the neurophysiology of the receiving bee because signs, in their variations, are circumscribed and repeatable, and the ensuing task wholly carried out by the individual. For hunting lions, a different scenario exists. There is no constant repetition of a limited range of sign features then acted upon by each individual: in the hunt there is continual cooperative novelty that each hunting lion's brain must absorb and act upon. Although the neurophysiology of each lion is capable of directing the lion's actions in relation to this novelty (and is vastly computationally complex), the missing feature is the communicative feature (of limited complexity without computation content) for the supraorganismic hunt program. This communicative feature that holds the lions together as the hunt is the signifying neural sign in each lion of what the causal neurophysiology is reacting to. Thus causally, lion A's neurophysiology reacts to the hunt environment; but it signifies this environment by the sign of it that it manufactures: the brain-sign. If you like, this sign is the elemental reason for the lion's actions (in the supra-organismic program). Reason, here, is specifically a signification of cause. But it is not cause. Bees need no such reasons, for there is nothing to be explained between them: their task is a rigid enactment of a specific way of behaving in their functional social structure, complex though it is.

Obviously, in the case of lions, the neural signification of the environment of the hunt program is a mutual reference. But it is not a reference to a mental subject. It is a reference that acts biologically between individual organisms facilitating cooperative action on a supraorganismic causal program to which, as the sign, it (the reference) has no access. A sign, a reason, a reference....and an agreement, since the zebra is the target of all the lions' neurophysiologies. Thus we see that dualism is removed, for the sign of causality as reason, reference and agreement, is a wholly physical function. Signs, unlike the Greek/Christian consciousness, or Dennett's causal intentional consciousness, are reducible (we will return to this).

There is no question: If the causal neurophysiology can manage the hunt program, why is there signification? because causality and signification are how dynamic cooperation takes place. Without signification, the hunt could not function. Indeed, we now have a genuine 
biogenesis for the phenomenon. ${ }^{14} \mathrm{We}$ do not separate mentality and action; brain-sign arises specifically to signify in the action process. Action (potential or actual) also effe cts memory or imagination, the conveying of the action-related past or possible. Causality and signification are distinct mechanisms: the ramifications of this will become evident.

It might occur to the reader that the notion of brain-sign is bizarre because no lion can look inside another lion's brain to see the sign. But this results from retaining the (dualist) notion of consciousness whilst trying to understand brain-sign theory. In the physical world, there is no perception. Brain-sign occurs for the supra-organismic program taking place across brains. It is a feature of that program, not some other way of specifying what happens concerning persons, because for a super-organism, there are no persons (or lion persons). To grasp brain-sign theory necessitates the giving up all associations with what consciousness is deemed to give. This requires practice. Indeed, to see that brain-sign is not epiphenomenal is a step in the grasp of the biology.

\subsubsection{Language}

Language is regarded as the distinctive feature of humans, distinguishing them from other species (though e.g. whales and dolphins remain enigmas on this, Rendell \& Whitehead, 2001). Because language allows humans to disengage from the rigidity of the actionconnection with the things of the world, it is supposed humans can consider those things symbolically and analytically. Moreover, since humans share language, propositional and expressive communication about states of the world and ourselves can be disengaged from those states. Language is the last fundamental difference between ourselves and other animals to which our self-regard clings.

Brain-sign theory disagrees. It claims the physical function of language has been misunderstood, for no account of biology is engaged. Chomsky, for example, uses the expression 'mind/ brain', thus indicating, since mind and brain are not explicitly determined (and deliberately so), that no biological theory underpins his language theory. ( $\mathrm{He}$ is skeptical, though, that language depends upon engaging consciousness. $)^{15}$

As with perception for hunting lions, we must specify how language is in the physical world. It seems to be that which we hear, and that which we read. But these are brain-sign functions, manufactured by the brain as casual signification. Surely language does communicative work, but not causal work for the organism. What, then, goes on with language?

In the physical world, language is structured marks on e.g. paper or a computer screen. The brain absorbs these marks by structured states of transduced electromagnetic radiation. In taking in these marks, the brain is not engaging with semantics. Such a supposition would have to explain how the neural brain could absorb structured marks as meaning and then employ it causally. There is no meaning in electromagnetic radiation or neural structure. Yet it seems, by the time we see language on the paper, we recognize it, that which has familiarity. Here, for example, is Fod or (1987) in Psychosemantics: "To understand a sentence is to grasp the thought that its utterance standardly conveys" (p151). But Fodor does not tell us what understand entails, nor grasp nor thought. No theory cogently specifies these as biology. So, as with perception, we reject the notion that a person's mind contains (in its inner

\footnotetext{
${ }^{14}$ The late Jeffrey Gray, in his 2004 book, states that there is no evidence to account for either the phylogeny or ontogeny of consciousness (pp117-120). Indeed, he stated (personal communication, 2002) that "no one understands why the brain needed to invent visual consciousness, since it can do so much processing of visual stimuli unconsciously." It is interesting, therefore, that he continued to support such a feature of the universe.

${ }^{15}$ Discussion on this topic by William Lycan (2003) can be found in his 'Chomsky on the Mind-Body Problem', with Chomsky's reply in the same volume.
} 
state) language to which they are orientated by (causal) recognitional understanding. ${ }^{16}$ The brain manufactures the state of 'seeing' the language and the sense of familiarity because it has so adapted by past exposure, and that is its physical function. (Similarly when we hear language from structured compression waves.) But why is that its function?

Our discussion of perception offers a ready answer. We 'see' or 'hear' language because that is neural signification in the communication process with others. We do not do anything because of what we see or hear, because our actions, or potential actions, are caused by the physical activity of our brains from absorbing the electromagnetic radiation or compression waves input. Learning to use language is learning communicative behavior in the physical world per se. Communicative behavior results from neural modification. In other words, there is no causal problem arising from semantics because semantics is irrelevant as is syntax. Semantics and syntax are the making sense as brain-sign, i.e. as our state 'takes itself to be' as a communicative mechanism.

Now we see the issue at 2.1 with interpreting fMRI scanning. In Neville et al.'s example (1998), what is likely illuminated in the Broca and Wernicke areas for both hearing readers of language and deaf ASL readers of signs is causal processing of language. The activation of the superior temporal gyrus in deaf readers is also causal processing, as is the case with hearers of spoken language. Brain-sign as communication, however, is a different function. Of course this does not solve brain-sign location, or its means of integration.

In being the brain-sign product 'seeing' or 'hearing', we have no access to the causes of our actions or potential actions. The brain could not overcome this division by its mechanism of self-interpretation from causal states to brain-sign. Verbal interpretation (as brain-sign) is bounded by the physical mechanisms of the brain itself which are not knowledge. ${ }^{17} \mathrm{We}$ misinterpret this adaptation fundamentally if we suppose (e.g.) expressed beliefs constitute causality. The brain believes nothing.

For example: A reader of this paper is traditionally supposed to be attempting to understand its content, and then perhaps make a decision on whether they agree with (we might say believe) it. But how could a neural brain weigh evidence and make a judgment as to rightness or wrongness (or truth or falsity)? A neural brain processes structured physical information, orientating itself towards action. Thus the reading of the paper is the process of colonization of the reader's neural structure and operation by the writer's brain. As brain sign, the reader 'sees' and 'understands' the words/ concepts. Because they are this brain-sign of 'seeing' and 'understanding', both the reader's and writer's brains can be in a state of signifying similarity concerning the potential action they might perform. Thus they (i.e. brain-signs) can be physical neural communication.

Still, what may be different is that the writer, as brain-sign, has the sense of rightness of the content, whereas the reader may have a sense of confusion or disagreement. So action likely would not coincide. But confusion and disagreement are no more accurate in terms of correspondence to an underlying reality than is the sense of rightness. The brain is a proactive/ reactive physical organ, not a container of the right and the wrong, not a parallel reality of the Greek/ Christian tradition.

The writer cannot persuade the reader of rightness. Persuasion entails mentalism. The writer's brain (biologically) colonizes the reader's brain in the physical process of reading: it is for brain science to ascertain the neural mechanism whereby the reader's actions might or might not result in positive influence from neural modification. ${ }^{18}$ It is also for brain science to

\footnotetext{
${ }^{16}$ Recall Heidegger (1927) in Being and Time: "Of course we are sometimes assured that we are certainly not to think of the 'subject's inside' and it's 'inner sphere' as a sort of 'box' or 'cabinet'. But when one asks for the positive signification of this 'inside' of immanence in which knowing [or understanding] is proximally enclosed...then silence reigns" (p87).

${ }^{17}$ In principle, this accords with Gazzaniga's (e.g. 2005) finding of the left brain interpreter in split-brain subjects. However Gazzaniga remains within the Greek/Christian traditionfor the anomalies of visual states, as with the left hemisphere's verbal fabrication, by not acknowledging that conscious interpretation cannot be causal for the organism. See Chapter 9: The Believing Brain, and note 5 for historical references.

${ }^{18}$ This is not meme theory, the invention of Richard Dawkins (1976), which assumes mentalism.
} 
determine the means by which a related brain-sign occurs. It is not for brain science to determine how brains interpret semantics.

One further observation. In reading or listening to language, as brain-sign we are not only what we 'see' and 'hear' linguistically. Also present are 'images', 'senses', 'feelings' of varying intensity. But how could hearing the word (e.g.) mountain evoke the associated images and senses? Mentalism would have it that one mental state causes another, the heard word mountain causes the image (but why this one?). There is no scientific explanation for this. Brain-sign theory proposes a different account. Structured electromagnetic radiation or compression waves, as physically transduced stimuli, activate neural structures generating the 'seen' or 'heard' word mountain, but also other facets like 'images' and 'sensations' because of causally associated neural architecture. What evidence do we draw for this? The experiments of Wilder Penfield (1958), where electrical stimulation of areas of the cortex (i.e. physical stimulation) generated comprehensive images, speech, sensations, apparently as quasi-memories.

\section{THE NATURE OF BRAIN-SIGN}

Although only a few characteristics of brain-sign have been mentioned, particularly perception and language, we can draw some helpful distinctions between it and consciousness.

\subsection{Brain-sign vs. consciousness}

The theory of consciousness must not only explain what mental entities are, it must explain mental processing. But how would the brain process in a modality different from what it is: physical causality? New theories appear regularly (e.g. Damasio 2000). ${ }^{19}$ But no explanation will reconcile the terms because the attempt to make the mind physical starts with a prescientific model devised for a different ontological rationale from the universe of physicality. ${ }^{20,21}$

Brain-sign theory bypasses this because its origins are in the material of which we are made. Two separate but linked mechanisms exist in the brain: one, the causal properties determining what the organism does; the other, a signifying status for communication between separate neurophysiologies derived from the causal mechanism.

Crucially, since each organism's history will result in a different neural/ causal relation to the world, consciousness = knowledge (that which is to a subject, 2.3) cannot exist, since brain-sign is an interpretation of each brain's different adapted causal relation to the world. For communication, however, brain-sign serves.

\footnotetext{
${ }^{19}$ Antonio Damasio's (2000) is a variation on higher order theory, but lacks explanation of how physicality becomes mentality. He says: "Many of us in neuroscience are guided by one goal and one hope: to provide, eventually, a comprehensive explanation for how the sort of neural pattern that we can currently describe with the tools of neurobiology, from molecules to systems, can ever become the multidimensional, space-and-time integrated image we are experiencing this very moment" (p322). In other words, he has no theory. His commitment to the Greek/Christian tradition is seen in the following: "The drama of the human condition thus comes from consciousness because it concerns knowledge obtained in a bargain that none of us struck: the cost of a better existence is the loss of innocence about that very existence" (p316). There is no characterisation here in terms of the physical world, nor is knowledge given any scientific definition.

${ }^{20}$ As Kim (2005) ranges over theories of reducibility proposed recently, "the new materialism", there is no mention, by the proposers, that both the function and nature of the mental are undefined as physicality. In other words, the predicament of us as experiencers-appearers (cf. 2.2.2) as biology is unnoticed. Dennett has taken the correct position in not accepting that consciousness can be ascertained entirely from within. The problem is, he does not disengage from the tradition adequately (cf. note 4).

${ }^{21}$ Cf. Peschl (1999): "It is not the goal of the neural representation system to map the environment as accurately as possible [i.e. perceptual knowledge] but to generate functionally fitting behavior" (p187).
} 


\subsection{Brain-sign as physical state}

Psychology, as a discipline, is founded upon many functions: perception, thought, feeling, etc., and innumerable others: hope, expectation, fear, indulgence, forgiveness, terror, and so on. The brain supposedly manufactures this vast complex so it can be causal as them.

If we banish psychology we eliminate these separate functions, and grant one causal kind of thing, the physical brain. This does not mean the brain itself is not structured in different functions; brain imaging indicates that they are located in specific areas (cf. 2.1), though how this operates is still in debate (cf. 3.1).

The derivative brain phenomenon, however, is of one kind. There are no psychological types as individual causal functions, but there are different signifying types of one kind: brain-sign.

Consciousness theory proposes we know the content our own states. They self-reveal how we approach the world, and what causes our actions in it. Brain-sign recasts the brain phenomenon functionally. For example, the brain does not engage a tree neutrally as a mere seeing of it, even though we (as brain-sign) may suppose we are gazing at it indifferently. This is because the brain is always action-orientated. Even if we do not seem emotionally or critically or attentionally orientated toward the tree, we cannot judge this from the phenomenon we are, for two reasons. Firstly, since the function of the phenomenon is communication with other brains, we cannot assess the neural nature of our state, i.e. its physical relation to the world actually. This is true specifically of attention (often a feature of 'psychological' testing). We do not choose to pay attention: our directedness is already a state of neural orientation, which a tester's brain may have caused us, as test-subjects, to be in. If we find we are paying attention, this is already a new orientation and entails loss of attention. Secondly, we can never judge of our own states, for there is no (mental) we to do so - no reflective capability.

If, for example, we 'reflect' that we find this tree attractive, are we judging of the tree or of our own state? Neither. The brain, creating brain-sign, signifies its causal status. Firstly, we 'see' the tree as beautiful because we are held before it as a result of its configuration and properties. In (expressibly) 'reflecting' that the tree is beautiful, our brains communicate their causal neural orientation. An animal, by contrast, may be held before a tree, but since it cannot externalize its state-it has no language causally to influence another animal-its brain-sign modality will not be expressible as 'language' that could alter another's causal state. Thus we see how so-called reflection can be explained for us (as neural expression), and why it cannot exist for most animals. But it is not reflection (a mental property).

Language is not some new magic feature of humans; it is an evolved extension of already existing mechanisms. ${ }^{22}$

Mentalism has been preoccupied with a life-long I, the subject of mental subjectivity, and the being of the person. But there are two counters to this, the first from brain-sign theory itself. Since brain-sign exists at this moment, and is derived from the causal status of the brain, and this will never be identically repeated, it is impossible for there to be an enduring I. The $I$ is an expression of the moment, and is welded to immediate content. The second is that since brain-sign performs no epistemological function for the brain (cf. 2.2.2), there is no way of founding the possibility that the I now was the I of the past or that of the future. The sense of the 'I' is a biological marker of this organism in communication now, not the Cartesian I of the soul, or the Kantian logical I by which experience can be consistently ours. ${ }^{23}$ This sense of the 'I', as of the conviction of right and wrong, or Wegner's feeling of will, is a construct of the brain for communication. Thus egoism, as a methodological-ontological principle for mental states, is disbarred. No I exists to experience, nor to whom appearances appear.

\footnotetext{
${ }^{22}$ Thus in the case of intentionalist and emergentist philosophers like John Searle (e.g. 2002), we eliminate the nature of what they propose exists (consciousness), and the need to fabricate a non-physical-world account of physicality.

${ }^{23}$ Kant was well aware that the continued existence of the I could not be proved, Third Paralogism: Of Personality.
} 


\subsection{Brain-sign as neural self-interpretation}

Mentalism proposes that physical input to the brain is turned into a different kind of existent and then processed as such by the brain. For action, this has to be turned back into physicality to cause motor results. The justification is that we appear to be this different existent. We have raised fundamental objections to that position. ${ }^{24}$

When we use the expression "neural self-interpretation" as brain-sign we mean the following. Action, for example in seeing a tree thence going up to touch it, results from the brain 'accessing' the tree as physical sensory and neural processing. This, then, translates into motor actions of the requisite type. To effect action, the brain uses edge detection, feature detection, motion detection, radiation wave-length detection, all of which are causal as physical states. Brain science should determine how the brain is so operative. Nonetheless the brain does have the capacity to make from them a neural image for communication purposes because the structure is 'presupposed' or 'prefabricated', as an assembly, in the action. To that image is added other features, as we have discussed, forming the whole of brain-sign at this moment. The inevitable delay between the brain's causal activity and what was taken to be our experience, the delay identified by Libet et al. (1983), is explained by the separate functions of causality and signification.

A crucial criterion validating the brain-sign account over mentalism is error, or misrepresentation. The image 'we see' is not a replication of what is there. It is an interpretation by the brain of what it takes to be there in terms of its causal relation to it, founded upon a history of adaptation. Thus error can enter the process because what we see is representation via causality. Thus we can see dog for cat, street light for tree, because the image does not covary with the world to mental processing, but communicates how the organism may or will causally react to what it takes to be there from its established states. ${ }^{25}$

The comparison we make for brain-sign, as a sign, is with the chameleon's skin. The chameleon's brain can make of its skin, a cellular structure, patterns and reflectance that work as a survival mechanism because a predator's brain cannot distinguish the chameleon from its surroundings. ${ }^{26}$ No requirement exists for ontological replication between the skin configuration and the surroundings. Similarly, brains communicate by making, of neural structures in the brain, brain-signs; states with no required ontological replication of the world. Thus, while mentality has no evolutionary precursor, brain-sign has. Signification is widespread in biology.

It is obvious, however, that brain-sign is hugely wasteful, since most communication is not established between organisms. But this derives from the fact that most of the brain's action orientation is not activated actually, in e.g. 'memory' and 'imagination'. However, the brain cannot switch itself off when it cannot communicate (cf. Wegner 2002, p28).

Although we cannot support Sartre's (1943) view of consciousness, of his many penetrating notions, that of the futile aim of the pour-soi (read consciousness) to be an en-soi (read the physical world) is remarkably apposite. Modern philosophy, in looking for mind brain reduction, expounds this futility. For we are not causally in the world as brain-sign; we are a sign of a state that is causally in the world, and to which, per se, we have no operative access.

\footnotetext{
${ }^{24}$ There have been attempts to circumvent this problem, notably that of O'Regan and Noë (2001). But this is stymied at its origin, since in proposing that "visual perception... [is] the activity of exploring the environment...mediated by knowledge of the... sensory-motor contingencies" (p943), they simply substitute one inexplicable knowledge, actual perception, by another, "of the sensory-motor contingencies". Also Noë (2005).

${ }^{25}$ The problem for covariationists is discussed by Cummins (1989). He says (p69): "Idealization is the only way to go with the idea that representation is covariation, for the covariationist, in the face of misrepresentation, must say, in effect, 'Well there would be covariation if things were nice." But idealization is not an option.

${ }^{26}$ Another explanation for the chameleon's skin patterning is to convey its 'emotional' state. For our purposes, the explanation is not crucial.
} 


\section{CONCLUSION}

What needs to be said on this topic has been minimally touched upon. However, these must be the last remarks.

As brain-sign, we seem to write what we think, reach for what we see, and comment on how we feel. However, 'thinking', 'seeing' and 'feeling' have no causal impact on writing, reaching and commenting. Indeed, it is because of their separation, and the misinterpreted evidence concerning this, that the theory of consciousness had to develop an unconscious, or non-conscious, to sustain itself. But that only made the problem of consciousness more obscure. For although we seem to write what we think, or reach for what we see, there is an unbridgeable gulf between e.g. our seeing and reaching, since they are caused by different mechanisms, and can result in a complete lack of correspondence between them. This is apparent in the Titchener circles illusion (Milner \& Goodale, 1995), where motor actions appear divorced from visual representation.

Indeed, science cannot depend upon mental states with their inner knowledge capacity, as traditionally supposed (cf. Giere 2000, p. 523). Science and technology are adaptive biological activities of the neural brain as neurophysiology (cf. Peschl, 1999).But science could not operate without the ability of inter-organism/ brain communication, which is brain sign.

Thus brain-sign, and the new neurophysiological mapping language for action, are not new names for familiar functions. Entirely new descriptive methods will be involved for each, reconstructing fundamentally our view of ourselves, and other organisms. The new neurophysiological mapping language allows description in terms of physicality, i.e. an escape from the futile attempt to locate psychology in the brain.

Brain-sign and consciousness offer different accounts of the brain phenomenon we are. How will we judge which is correct? As with all topics in science, the answer is: by experiment-though this will be bounded by the function of brain-sign itself. What is certainly the case, as this text indicates, is that brain-sign is the only comprehensive account that meets the current evidence. Moreover, it is the only account that begins from the physical world, and offers a scientific analysis of how the phenomenon could have evolved and function in the brain, with a reducible ontology and necessary biological role.

\section{REFEREN CES}

Bear, M.F., Connors, B.W., Paradiso, M.A. (2006). Neuroscience: Exploring the Brain, third edition, Lippincott, Williams and Wilkins.

Beaumont, J.G. (1999) Neuropsychology entry, in The Blackwell Dictionary of Neuropsychology, J.G. Beaumont, P.M. Knealy, M.J.C. Rogers ed s., Blackw ell.

Block, N. (1995) On a confusion about a function of consciousness, Behavioral and Brain Sciences, 18, 2 , 227-287.

Block, N. (2001) Paradox and cross purposes in recent work on consciousness, Cognition, 79, 1\&2, 197219, volume published as The Cognitive Neuroscience of Consciousness, N. Dehaene ed., MIT 2001.

Chalmers, D. (1996). The Conscious Mind, Oxford University Press.

Chomsky, N. (1959). Review of Skinner's Verbal Behavior, Language, 35, 26-58. Chomsky, N. (2003) Reply to Lycan, as Lycan (2003), 255-263

Churchland, P.M. (1995). The Engine of Reason: The Seat of the Soul, MIT Press.

Churchland, P.S. (2002). Brain-Wise: Studies in Neurophilosophy, A Bradford Book, MIT Press.

Clark, A. \&Prinz, J. (2004). Putting Concepts to Work: Some Thoughts for the Twenty First Century, Mind and Language, 19:1, 57-69.

Cummins, R. (1989). Meaning and Mental Representation, MIT Press.

Damasio, A. (2000). The Feeling of What Happens: Body, Emotion and the Making of Consciousness, William Heinemann.

Davidson, D. (1970) Mental Events, in Experience and Theory, L. Foster, J.W. Swanson eds., University of Massachusetts Press, 79-101.

Dawkins, R. (1976). The Selfish Gene, Oxford University Press.

Dehaene, S. \& Naccache, L. (2001). Towards a cognitive neuroscience of consciousness: basic evidence and a workspace framew ork, Cognition 79, 1\&2, 1-37, published as Block (2001). 
Dennett, D. (1991a). Consciousness Explained, Little Brown.

Dennett, D. (1991b). Real Patterns, Journal of Philosophy, 89, 27-51.

Dennett, D. (1994). Dennett entry, in A Companion to the Philosophy of Mind, ed. S. Guttenplan, Blackwell, 236-244.

Dennett, D. (1996). Kinds of Minds, Weidenfeld \& Nicolson.

Dennett, D. (2004). Calling in the Cartesian loans, comment on Wegner. Behavioral and Brain Sciences, 27, $5,661$.

Edelman, G.M. \& Tononi, G. (2000). Consciousness: How matter becomes imagination, Allen Lane.

Erneling, C. E.\&Johnson, D.M. eds. (2005). The Mind as Scientific Object, Oxford University Press.

Gazzaniga, M.S. (2005). The Ethical Brain, Dana Press.

Giere, R.N. (2000). Theories, in A Companion to the Philosophy of Science, W.H. Newton-Smith ed., Blackwell, 515-527.

Gray, J. (2004) Consciousness: Creeping up on the hard problem, OxfordUniversity Press.

Hebb, D. (1949). The Organisation of Behaviour: A Neuropsychological Theory, Wiley.

Heidegger, M. (1927). Being and Time, trans. J. Macquarrie \& E. Robinson (1962), Basil Blackwell.

Heidegger, M. (1975). Early Greek Thinking, trans. D.F. Krell \& F.A. Capuzzi, Harper and Row .

Johnson, D.M. (2005). Introduction to The Mind as Scientific Object, in Erneling \& Johnson eds. (2005), 311.

Kant, I. (1781,1787). Critique of Pure Reason, trans. N.K. Smith (1933), $2^{\text {nd }}$ edition, Macmillan.

Kim, J. (2003). Blocking Causal Drainage and Other Maintenance Chores with Mental Causation, Philosophy and Phenomenological Research, LXVII, 151-176.

Kim, J. (2005). Physicalism, or Something Near Enough, Princeton University Press.

Kirk, G.S., Raven, J.E., Schofield, M. (1983). The Presocratic Philosophers, second edition, Cambridge University Press.

Koch, C. (2004). The Quest for Consciousness, Roberts \& Company.

Kuhn, T.S. (1962). The Structure of Scientific Revolutions, University of Chicago Press.

Libet, B., Curtis, A.G., Wright, E.W., Pearl, D.K. (1983). Time of conscious intention to act in relation to onset of neural activity (readiness potential). The unconscious initiation of a freely voluntary act, Brain 106, pp 623-642.

Lycan, W.G. (2003). Chomsky on the Mind-Body Problem, in Chomsky and his Critics, L.M. Antony \& N. Hornsteined s., Blackwell, 11-28.

Milner, A. \& Goodale, M. (1995). The Visual Brain in Action, Oxford University Press.

Neville, H.J., Bavelier, D., Corina, D., Rauschecker J., Karni, A., Lalwani, A., Braun, A., Clark, V., Jezzard, P., Turner, R. (1998). Cerebral organization for language in deaf and hearing subjects: biological constraints and effects of experience, Proceedings of the National Academy of Sciences USA, 95, 022-929.

Noë, A. (2005). Action in Perception, Brad ford Books, MIT Press.

O'Regan, J.K. \& Noë, A. (2001). A sensorimotor account of vision and visual consciousness, Behavioral and Brain Sciences, 24:5, 939-1031.

Papineau, D. (2003). Theories of Consciousness, in Consciousness: New philosophical perspectives, Q. Smith \& A. Jokic eds., Clarendon Press Oxford, 353-383.

Penfield, W. (1958). The Excitable Cortex in Man, Liverpool University Press

Peschl, M.F. (1999). The development of scientific concepts and their embodiment in the representational activities of cognitive systems, in The Nature of Concepts Evolution, structure and representation, P. van Looke ed., Routledge, 184-214.

Rendell, L. \& Whitehead, H. (2001). Culture in whales and dolphins, Behavioral and Brain Sciences, 24, 2, 309-382.

Rizzolatti, G., Fadiga, L., \& Fogassi, L. (1996). Premotor cortex and the recognition of actions, Cognitive Brain Research, 3, 131-141.

Ross, D., Spurrett, D. (2004). What to say to a skeptical metaphysician: A defense manual for cognitive and behavioral scientists, Behavioral and Brain Sciences, 27, 5, 603-647.

Sartre, J.-P. (1943). Being and Nothingness, trans. H.E. Barnes (1958), Routledge.

Seager, W. (1999). Theories of Consciousness, Routled ge.

Sterelny, K. (2003). Thought in a Hostile World: The Evolution of Cognition, Blackw ell.

Stent, G.S. (2005). Epistemic Dualism, in Erneling \& Johnson ed s. (2005),144-164.

Wall, P. (1999) Pain: The science of suffering, Wiedenfeld and Nicholson.

Watson, G. (1995). Free Will, in A Companion to Metaphysics, J. Kim \& E. Sosa ed s., Blackwell, 175-182.

Watson, G. ed. (2003). Free Will, second edition, Oxford University Press.

Wegner, D.M. (2002). The Illusion of Conscious Will, MIT Press.

Wegner, D.M. (2004). The illusion of conscious will, Behavioral and Brain Sciences, 27, 5, 649-692. 